\title{
Intramedullary spinal cavernoma: clinical presentation, microsurgical approach, and long-term outcome in a cohort of 48 patients
}

\author{
Matthias Reitz, MD, ${ }^{1}$ Till Burkhardt, MD, ${ }^{1}$ Eik Vettorazzi, MSc, ${ }^{2}$ Frank Raimund, MD, ${ }^{3}$ \\ Erik Fritzsche, MD, ${ }^{3}$ Nils Ole Schmidt, MD, ${ }^{1}$ Jan Regelsberger, MD, ${ }^{1}$ Manfred Westphal, MD, ${ }^{1}$ and \\ Sven Oliver Eicker, MD'1
}

'Department of Neurological Surgery; ${ }^{2}$ nstitute of Biometry and Epidemiology, University Medical Center Hamburg-Eppendorf; and ${ }^{3}$ Department of Spinal Surgery, Asklepios Hospital Wandsbek, Hamburg, Germany

\begin{abstract}
OBJECT Intramedullary spinal cavernoma (ISC) is a rare entity and accounts for approximately $5 \%-12 \%$ of all spinal vascular pathologies. The purpose of the present study was to examine the influence of clinical presentation, localization, and different surgical approaches on long-term outcome in patients treated for ISC.

METHODS The authors performed a retrospective single-center study of 48 cases of ISC treated microsurgically over the past 28 years. Analyzed factors included preoperative clinical history, microsurgical strategies, neurological outcome (American Spinal Injury Association [ASIA] grade, Epstein and Cooper grade), and the occurrence of postoperative spinal ataxia. Univariate analysis was performed to identify factors influencing long-term outcome.

RESULTS Preoperatively, $18.8 \%$ of all patients experienced a slow, progressive decline in neurological function and $33.3 \%$ suffered repetitive episodes of acute neurological deterioration over a time frame of months to years. Moreover, $16.7 \%$ noted the sudden onset of a severe neurological deficit, whereas $25 \%$ experienced the sudden onset of symptoms with a subsequent gradually progressive decline in neurological function. On long-term follow-up after treatment (mean $\pm \mathrm{SD}, 79.3 \pm 35.2$ months), $70.8 \%$ of patients showed no change in neurological function, $6.3 \%$ suffered from a decline, and $22.9 \%$ improved neurologically. Thoracolumbar localization $(p=0.043)$, low preoperative Epstein and Cooper grade for the lower extremities $(p<0.001)$, and a low preoperative ASIA grade $(p<0.001)$ were identified as factors associated with an unfavorable outcome (ASIA Grade A-C). The rate of spinal ataxia related to surgical approach was $16.7 \%$.
\end{abstract}

CONCLUSIONS Postoperative neurological function in ISC patients is determined by the preoperative neurological status. On long-term follow-up after microsurgical treatment, $93.7 \%$ of patients presented with a stable or improved condition (ASIA grade); thus, definite microsurgical treatment should be considered as long as patients present with only mild symptoms after the diagnosis of symptomatic ISC.

http://thejns.org/doi/abs/10.3171/2015.5.FOCUS15153

KEY WORDS spinal cavernoma; microsurgery; spinal cord; vascular malformation

I NTRAMEDULLARY spinal cavernoma (ISC) is a rare vascular disease and accounts for $5 \%-12 \%$ of all spinal vascular pathologies. ${ }^{17,28,34}$ The incidence of cavernoma located in the CNS, including the brain and spinal cord, is about 1.9 cases/100,000 persons/year with $3 \%-5 \%$ of lesions located in the spinal cord. ${ }^{16,29}$ An ISC may become clinically apparent with the acute onset of neurological deficits and a wide range of symptoms due to either an acute macrohemorrhage forming a spaceoccupying lesion, possibly accompanied by edema of the spinal cord, or a worsening of preexisting symptoms as the result of recurrent hemorrhage. However, repetitive intralesional microhemorrhages can lead to a more slowly progressive decline in neurological function. ${ }^{31}$ The sudden onset of pain is rarely seen but is most likely the result of subarachnoid hemorrhage..$^{29}$

ABBREVIATIONS ASIA = American Spinal Injury Association; EC = Epstein and Cooper; IOM = intraoperative electrophysiological monitoring; ISC = intramedullary spinal cavernoma; MEP = motor evoked potential.

SUBMITTED March 30, 2015. ACCEPTED May 14, 2015.

INCLUDE WHEN CITING DOI: 10.3171/2015.5.FOCUS15153.

DISCLOSURE The authors report no conflict of interest concerning the materials and methods used in this study or the findings specified in this paper. 
A number of published case reports and case series of ISC have documented surgical treatment options as well as the natural history of the disease. ${ }^{6,14,22,35,38}$ For the purpose of diagnosis, MRI still represents the gold standard, showing a typical hyperintense lesion on native T2weighted sequences, usually surrounded by a hypointense hemosiderin rim after hemorrhage (Fig. 1). With respect to causative treatment options, complete microsurgical removal of the pathology is recognized as the therapy of choice whenever possible. ${ }^{2,8,11,23,25,27,37}$ Approaches to the spinal cord are performed either directly to the pathology in cases of ISCs reaching the pial surface or via the central dorsal sulcus (midline myelotomy) for deep-seated lesions. Spinal cord access via the dorsolateral entry zone is especially suitable for superficial lateral pathologies by opening the dentate ligament and gently rotating the spinal cord.$^{30}$ Custom-tailored approaches are mandatory to minimize perioperative complications, achieve complete resections, and optimize postoperative outcome. ${ }^{15}$ Indications for microsurgical removal are present when an ISC becomes clinically apparent and presents as surgically accessible. The annual rate for a first hemorrhage is up to $4.5 \%$ in retrospective series, assuming lesions were present since birth. For recurrent hemorrhage, the annual rate is up to $66 \%$ per patient per year, possibly leading to further, rapid, permanent neurological deterioration. $.1,4$

Little data correlate clinical, anatomical, and surgical aspects of ISCs with the long-term neurological outcome of surgically treated patients. The present study was conducted to evaluate long-term outcome in a cohort of 48 microsurgically treated patients with ISC and to identify factors influencing neurological status after treatment to facilitate decision making for clinicians confronted with ISC.

\section{Methods}

We performed a retrospective analysis of the medical records between 1986 and 2014, identifying all patients with the diagnosis of an ISC treated microsurgically at our neurovascular center. Other vascular pathologies of the spinal cord such as spinal dural arteriovenous fistula or spinal arteriovenous malformations were excluded. Patient histories were assessed using the 4-type scale introduced by Ogilvy et al., which discriminates between acute and chronic progression as well as phases of neurological recovery (Table 1). ${ }^{31}$ Long-term functional outcome was assessed using the American Spinal Injury Association (ASIA) impairment scale, which was applied pre- and postoperatively and on long-term follow-up. As an additional clinical parameter, the Epstein and Cooper (EC) grading system for intramedullary tumors was applied for all patients preoperatively and immediately postoperatively. ${ }^{10,21}$ Favorable outcome on long-term follow-up was defined as an ASIA grade of D or E. For the assessment of dorsal column function after dorsal myelotomy, patients were additionally seen in the outpatient clinic and neurologically examined (Romberg's sign, Unterberger's test, tandem gait assessment, heel-shin test).

Using a 3-pin Mayfield skull clamp if the lesion was located in the cervical spine or in the cervicothoracic region, we performed surgery with the patient in prone position.

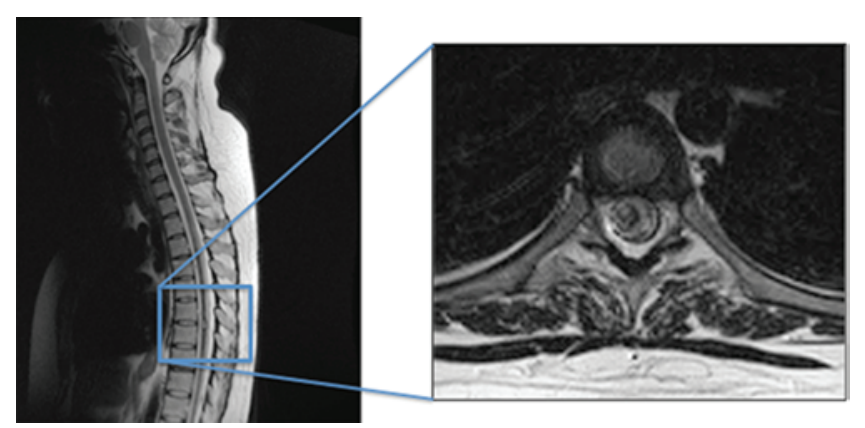

FIG. 1. Left: Sagittal T2-weighted MR image of the spinal column showing a thoracic ISC between T-6 and T-7. Right: Axial T2-weighted enlarged image of the same pathology in the left panel showing an inconsistent signal with a hint of a hypointense rim, suggestive of an ISC.

We utilized various approaches to the spinal cord (for example, laminotomy, laminectomies, hemilaminectomies), depending on the extent and location of the pathology (Fig. 2). To improve targeting of the approach and minimize surgical trauma, ultrasonography was used before opening the dura mater. ${ }^{3,32}$ Myelotomy was performed via the posterior median sulcus (dorsal midline entry zone), lateral through the dorsolateral entry zone, or directly into the pathology (Fig. 3). Microsurgical dissection was performed using the surrounding gliotic layer as a preparation margin. In some cases, a $\mathrm{CO}_{2}$ surgical laser system (SLS-25, Surgilase) was used to dissect without traction. Throughout the preparation, all efforts were made to protect the surrounding spinal cord vessels (Figs. 4 and 5). Intraoperative electrophysiological monitoring (IOM) was applied in all cases treated after 1996. In these cases, somatosensory evoked potentials along with motor evoked potentials (MEPs) and morphological D-wave changes were analyzed. After complete microsurgical removal of the ISC, the arachnoid layer was sutured (7.0 Ethilon, Ethicon), the dura was closed, and the vertebral arches were fastened in place (in cases of laminotomy).

Neuropathologists routinely analyzed the resected specimen. Staining procedures utilized hematoxylin and eosin, van Gieson's elastic stain, Masson's trichrome stain, and Turnbull's stain for siderin, all following standard laboratory procedures. Histologically, the most frequent differential diagnosis was melanocytoma.

Descriptive statistics were used to characterize the study population. The Student t-test was used to compare means of metric variables and the likelihood-ratio chisquare test was used for categorical variables whenever appropriate. Univariate logistic regression analysis was used to identify potential factors influencing long-term clinical outcome (ASIA grade, EC grade). A p $<0.05$ was considered statistically significant. All statistics were performed using SPSS (IBM SPSS Statistics for Windows, version 22.0, IBM Corp.). Values are expressed as the mean \pm standard deviation, unless indicated otherwise.

\section{Results}

Out of a series of 397 patients with intramedullary spinal cord lesions treated at our institution during the study period, we identified 48 patients with ISC (12.1\%). Twenty- 
TABLE 1. Ogilvy classification of preoperative clinical history

\begin{tabular}{cc}
\hline Type & Description \\
\hline 1 & $\begin{array}{c}\text { Pattern of discrete and acute episodes of neurological dete- } \\
\text { rioration over mos to yrs separated by various degrees of } \\
\text { recovery }\end{array}$ \\
\hline 2 & Slow, progressive decline in neurological function \\
\hline 3 & Acute onset of symptoms followed by rapid neurological decline \\
\hline 4 & $\begin{array}{c}\text { Acute onset of mild symptoms followed by a gradually progres- } \\
\text { sive decline in neurological function over wks to mos }\end{array}$ \\
\hline
\end{tabular}

three females (47.9\%) and 25 males (52.1\%), with a mean age of $41.3 \pm 15.6$ years, had ISCs located in the thoracic (56.3\%), cervical (39.5\%), and thoracolumbar (4.2\%) regions.

Preoperatively, $18.8 \%$ of patients reported a slow, progressive decline in neurological function, $33.3 \%$ showed discrete and acute episodes of neurological deterioration with various degrees of recovery in between, and $41.7 \%$ of patients reported an acute onset of symptoms followed by either a rapid $(16.7 \%)$ or gradually progressive $(25.0 \%)$ decline of neurological function; the remaining $6.2 \%$ presented with incidental findings of ISC. Neurological symptoms were defined as sensory disorders (for example, dysesthesias, impaired proprioception), motor disabilities (for example, paresis), or autonomic dysfunction (for example, disturbances in bladder or bowel control).

The time span from the onset of symptoms to the diagnosis of ISC varied between hours in cases of acute and severe neurological impairment, and 96 months in cases of mild neurological impairment (mean $16.1 \pm 20.3$ months).

The treatment of choice was complete microsurgical removal, which was performed in all 48 cases. Concerning the operative approach to the spinal cord, various degrees of bony resection were performed. For small and lateral ISCs reaching the surface, hemilaminectomies (1-level: $8.3 \%, \mathrm{n}=4$; 2-level: $2.1 \%, \mathrm{n}=1$ ) were found suitable and supplied a sufficient intraoperative overview. On the other hand, deep or large ISCs required more extensive approaches (1- or 2-level laminectomies: $18.8 \%, \mathrm{n}=$ 9; 1 - or 2-level laminotomies: $54.2 \%, \mathrm{n}=26$ ) allowing for an overview of the complete spinal cord anatomy (Fig. 2). Other, much more infrequently performed approaches constituted ventral approaches $(2.1 \%, \mathrm{n}=1)$ and, for example, combined suboccipital and cervical dorsal laminectomies or interlaminary fenestrations $(14.6 \%, \mathrm{n}=7)$.

Microsurgical myelotomy was performed either via the posterior median sulcus $(37.5 \%)$ or directly in cases in which the lesion had contact with the surface (54.2\%). In 4 patients (8.3\%) a lateral approach (lateral entry zone) with division of the dentate ligament on one side was performed (Fig. 3B). Other custom-tailored options included a ventral approach to the cervical spine when the ISC was located in the ventral spinal cord, extending to the medullary surface, which was performed once (Fig. 3C). ${ }^{15}$

Functional outcome assessment using the ASIA impairment scale immediately postoperatively before discharge demonstrated that $54.2 \%$ of the patients were unchanged neurologically, $33.3 \%$ had worsened, and $12.5 \%$ had improved compared with the preoperative state.

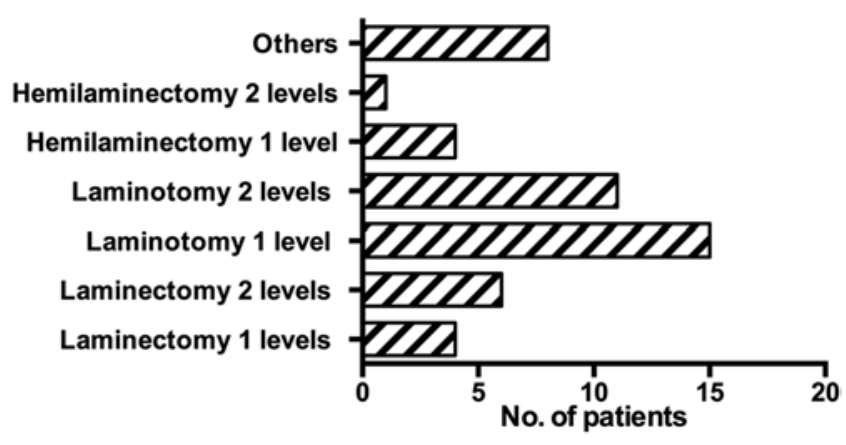

FIG. 2. Approaches to the spinal column varied depending on the extent and localization of the ISC. The most frequent approaches included 1- or 2-level laminotomies or laminectomies. In some cases of lateral ISC, hemilaminectomies were sufficient for accessing the spinal cord. We also used combined approaches to the cervical spinal cord, making decompression of the foramen magnum and laminotomies of $\mathrm{C}-1$ necessary.

Worsening or improvement was defined as a change by at least 1 grade on the scale. On long-term follow-up (mean $79.3 \pm 35.2$ months) $70.8 \%$ of the patients demonstrated no change in neurological function compared with their preoperative status, $6.3 \%$ had worsened, and $22.9 \%$ had improved (Fig. 6). Overall, 83\% of patients presented with a good ASIA grade (D or E) on long-term follow-up.

Factors possibly influencing the ASIA grade on longterm follow-up were identified by univariate logistic regression analysis. Three factors were associated with significant effects on the long-term postoperative ASIA grade: thoracolumbar localization, a low preoperative EC grade for the lower extremities, and a low preoperative ASIA grade (Table 2).

Regarding ISC localization, pathologies located in the thoracolumbar spinal cord $(n=2)$, as opposed to the cervical or thoracic, did show a greater risk for a postoperative ASIA grade of A-C. In our series, 2 patients with thoracolumbar ISCs were identified, and both of them had an ASIA grade of $\mathrm{C}$ on long-term follow-up. Forty-six patients with either cervical or thoracic ISC had a higher probability of presenting with an ASIA Grade E or D on long-term follow-up ( $p=0.043$; Figs. 6 and 7).

The preoperative clinical status as reflected by the lower extremities EC grade as well as the preoperative ASIA grade was shown to have a significant impact on the longterm ASIA grade (both $\mathrm{p}<0.001$ ).

Of the 48 patients included in our study, 18 (37.5\%) were also seen on an outpatient basis in the Department of Neurology and underwent physical examination with a focus on the clinical aspects of spinal ataxia. Because of the long follow-up period, patients were often not available for a physical examination. All 18 of these patients had been treated within the past decade. Seven patients (38.9\%) experienced moderate or severe neurological impairments prior to the operation (for example, paraparesis or previously existing spinal ataxia). Postoperatively, 3 patients $(16.7 \%)$ showed signs of newly occurring spinal ataxia. In all 3 of these cases, midline myelotomies were performed to access the pathology (approach-related ataxia, median follow-up for this group: 48 months).

One patient suffered from a recurrence of an initially 


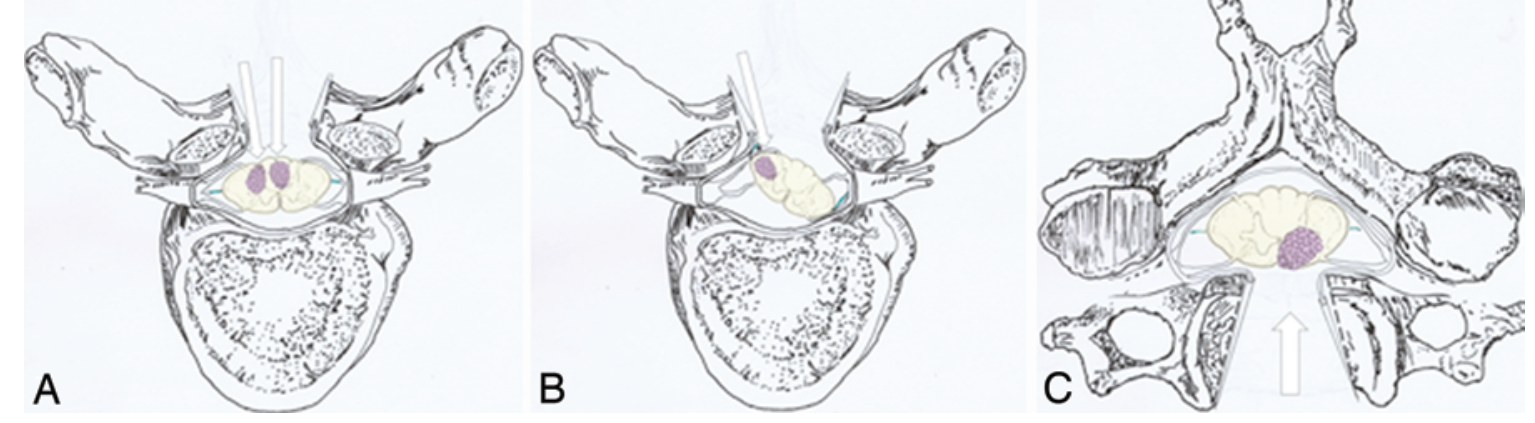

FIG. 3. Illustration of the 3 common thoracic myelotomies to approach a cavernous malformation (A and B) and a ventral cervical approach in the case of a cavernous malformation on the surface of the ventral spinal cord (C). The approach to the posterior and posterolateral malformation is through the median sulcus or the dorsal root entry zone (A). For lateral cavernous lesions (B), the dentate ligament (blue) must be divided to gently rotate the spinal cord. Myelotomy must be performed in the middle between the dorsal and ventral nerve roots on the ventral side of the dentate ligament. Optionally, additional bone removal must be performed on the ipsilateral side of the lesion. The ventral approach to a deep cavernous malformation on the ventral surface of the spinal cord after corpectomy is illustrated (C). Copyright Sven Oliver Eicker. Published with permission.

completely microsurgically resected thoracic ISC. She underwent reoperation with a straightforward approach and has not suffered another recurrence in 11 years of additional follow-up. Regarding perioperative complications, 1 patient suffered from an acute epidural hematoma, which was immediately evacuated; this patient had no postoperative neurological deterioration on follow-up. In the presented cohort, no CSF leakages or wound infections leading to a second surgical intervention occurred.

One patient required cervical spondylodesis 4 months after extirpation of a cervical ISC because of segmental instability leading to a secondary kyphosis. In this patient, the initial cervical approach had been performed via a 2-level laminotomy.

\section{Discussion}

In this study, factors influencing long-term clinical outcome and microsurgical strategies are presented along with the preoperative clinical histories of 48 microsurgi-
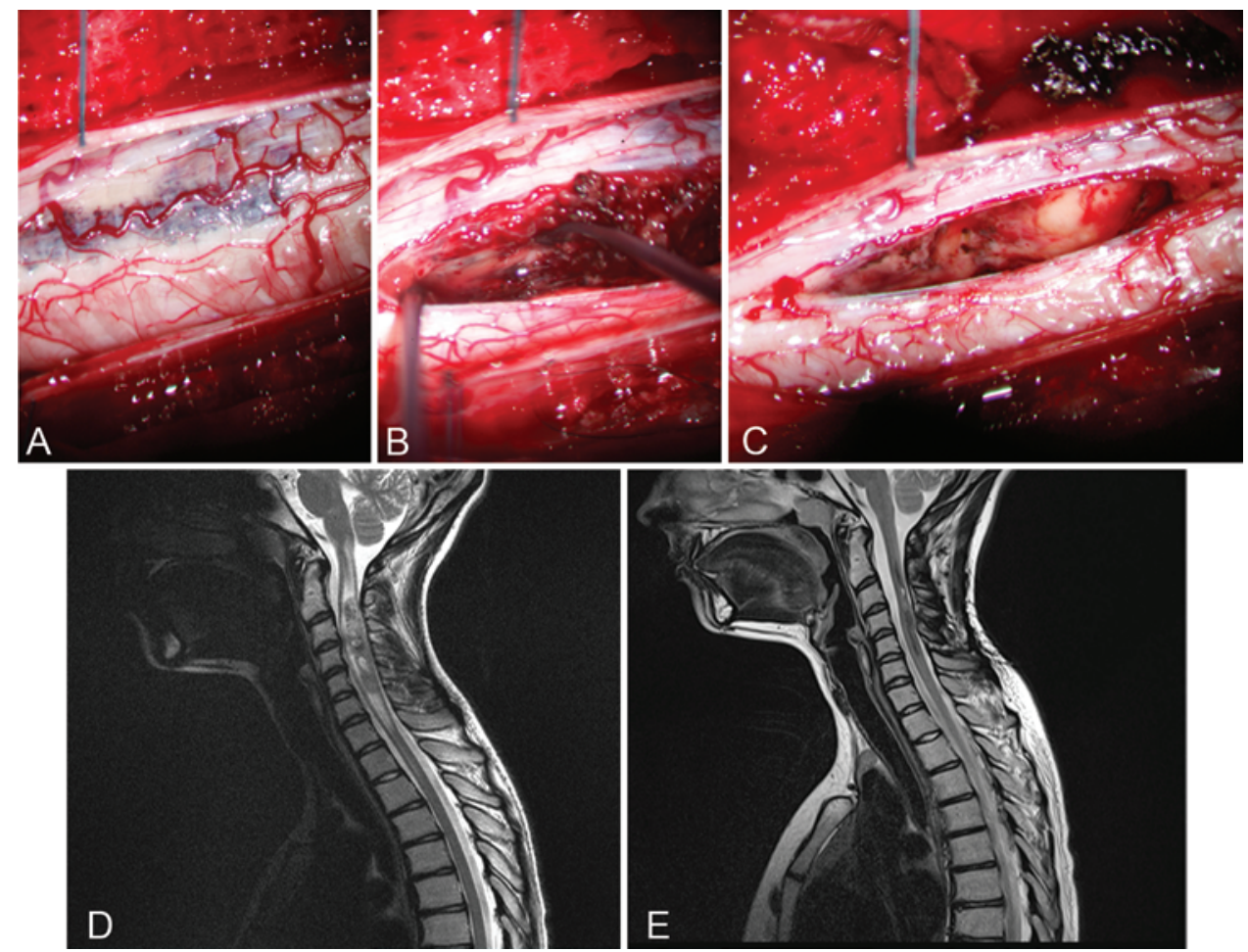

FIG. 4. Microsurgical removal of a large cervical ISC located at C-3 and C-4. After a midline incision sparing the medullary vessels (A), careful microsurgical preparation defining the cavernoma margins is performed (B), resulting in a complete extirpation of the pathology, leaving a resection cavity (C). Multilevel cavernoma on a preoperative T2-weighted MR image (D) with a mixed T2 signal and segmental edema. After microsurgical removal of the ISC, sagittal T2-weighted MRI (E) showed persisting cord hemosiderosis and confirmed complete removal of the ISC with diminishing cord edema. 

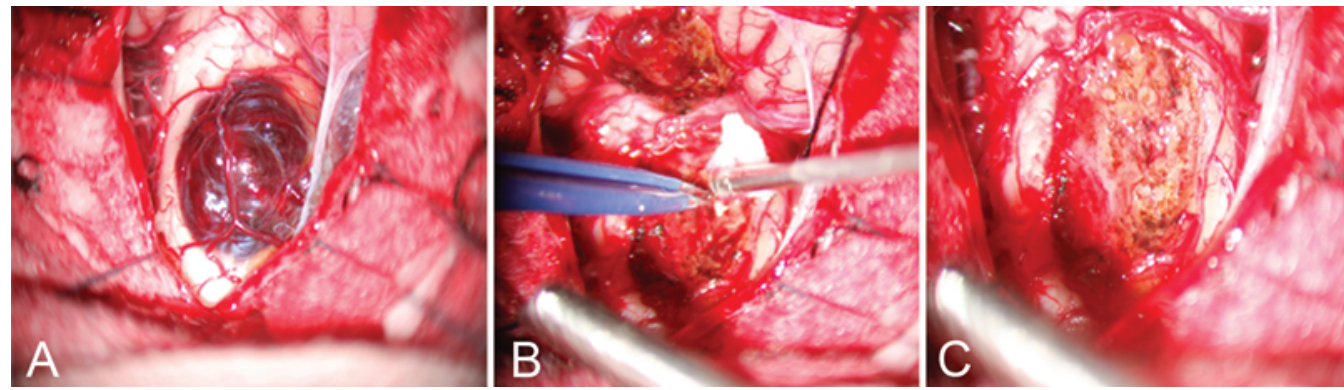

FIG. 5. Microsurgical removal of an exophytically growing spinal cavernoma (A) in the cervical spinal cord (C-4). Preparation of the cavernoma using bipolar forceps with coagulation of the nourishing vessels (B), leaving the cavernoma bed after complete extirpation of the pathology $(\mathrm{C})$.

cally treated ISC patients. Factors significantly associated with an unfavorable outcome (defined as ASIA Grades A-C) include a thoracolumbar localization, a low preoperative EC grade for the lower extremities, and a low preoperative ASIA grade. On long-term follow-up, 93\% percent of surgically treated patients presented with an improved or unchanged neurological status compared with their preoperative status, and $83 \%$ of patients had an ASIA Grade D or E.

The major goal of surgical treatment is the complete and immediate resection of the ISC without permanent neurological deterioration. Currently, the feasibility of microsurgical treatment along with patterns of clinical manifestations has been recognized, and the microsurgical removal of ISC is recommended when the pathology becomes clinically apparent and appears accessible. . $^{17,36}$

If symptomatic patients present with an ISC showing signs of hemorrhage on MRI, microsurgical removal is suggested within 2 and up to 6 weeks after the disorder becomes clinically apparent. Results from previous studies of cavernoma surgery, for example, in the brainstem, suggest early microsurgical treatment if anatomically reasonable. If surgery is delayed for several weeks, patients are at greater risk for neurological deterioration. ${ }^{5}$ This finding is most likely attributable to scarring around the cavernoma so that dissection becomes more invasive and increases the risk for neurological deficits. If surgery is performed too early, edema and vulnerability of the spinal cord due to hemorrhage may lead to postoperative deterioration. If surgery is performed too late, gliosis and limited space may contribute to aggravated surgical removal with possibly negative effects on clinical status after surgery.

Observation, on the other hand, is recommended for both asymptomatic lesions not reaching the pial layer and symptomatic deep-seated lesions with minimal or transient symptoms. ${ }^{17}$ In a recent series focusing on the conservative treatment of ISC, patients displaying sensory and/or motor deficits were shown to profit from surgical treatment. ${ }^{20}$ Only asymptomatic patients or patients with pain as the only symptom were shown to justify a "wait and see" strategy.

In our cohort, $33.3 \%$ of patients had a worse AISA grade in the immediate postoperative phase compared with their preoperative status. This immediate deterioration was most likely attributable to intraoperative intramedullary dissection, and the rate fell to $6.3 \%$ of patients with permanent worsening on long-term follow-up after surgery. In the literature, transient neurological worsening after surgery occurs in up to $50 \%$ of cases, but on longterm follow-up after surgery permanent worsening decreases to $0 \%-20 \% .^{1,13,18,37}$

Regarding the assessment of spinal ataxia, especially after myelotomy, the ASIA grade does not accurately reflect the true degree of impairment since it mostly addresses motor deficits due to muscle strength. Three (16.7\%) of 18 patients, who on follow-up were neurologically examined with an emphasis on ataxia, were found to have newly diagnosed spinal ataxia postoperatively. All of these patients had been treated with midline myelotomy to access the pathology. The implications of these findings are hard to determine since preoperative neurological deficits may distort the true incidence of newly occurring spinal ataxia postoperatively, making an interpretation of the findings (preoperative deficit versus complication versus operative morbidity due to myelotomy) even more difficult.

Intraoperatively, the lack of substantial deterioration in IOM with a special focus on D-wave changes confirms the surgical strategy and helps to avoid a worsening neurological outcome postoperatively. ${ }^{12,24,33}$

A major prognostic factor determining neurological outcome was the preoperative neurological status (ASIA grade: $\mathrm{p}<0.001$ and EC grade for the lower extremities: $\mathrm{p}$ $<0.001$ ), which matches the results from another previous series. ${ }^{36}$ Both scores focus on motor function of the lower extremities and can be interpreted together.

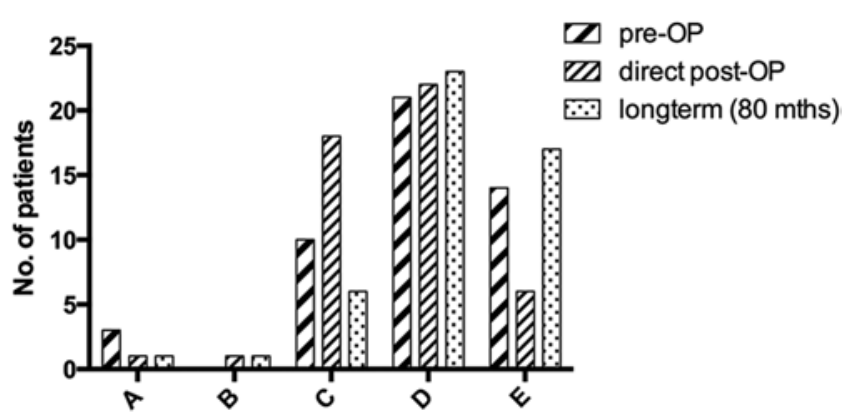

FIG. 6. On long-term follow-up, $83 \%$ of patients presented with an ASIA grade of D or E. Directly after the operation, $33.3 \%$ of patients experienced temporary deterioration of their neurological status, as measured using the ASIA scale. Permanent neurological deterioration according to this scale was seen in $6.3 \%$ of patients. 
TABLE 2. Univariate ordinal logistic regression analysis of variables tested possibly affecting postoperative ASIA long-term outcome*

\begin{tabular}{lc}
\hline \multicolumn{1}{c}{ Variable } & p Value \\
\hline Age & 0.316 \\
\hline Sex & 0.657 \\
\hline Localization & 0.043 \\
\hline Onset of symptoms until time of treatment & 0.417 \\
\hline Spinal approach & 0.110 \\
\hline Myelotomy & 0.068 \\
\hline Laser use & 0.711 \\
\hline Preop clinical course & 0.761 \\
\hline Preop EC grade UE & 0.881 \\
\hline Preop EC grade LE & $<0.001$ \\
\hline Preop ASIA grade & $<0.001$
\end{tabular}

LE = lower extremity; UE = upper extremity.

* Localization, preoperative EC grade as well as preoperative ASIA grade significantly influence long-term postoperative ASIA grade.

However, $16.7 \%$ of patients suffered preoperatively from the acute onset of symptoms associated with severe neurological deficits. Given the risk for severe permanent neurological deficits and rapid neurological decline combined with the potential for a good postoperative outcome, early microsurgical therapy is strongly advocated whenever the lesion is accessible and patients suffer from only mild symptoms. From our point of view, symptomatic patients with deep-seated lesions and progressive mild symptoms can also be safely treated without the risk of postoperative deterioration, since the annual initial hemorrhage risk is estimated to be around $4.5 \%$ and higher, especially if one considers that rapid neurological deteriorations can occur. ${ }^{37}$ At what time point mild symptoms become progressive may be very subjective; therefore, neurological symptoms must be closely monitored in the case of deepseated lesions managed with a conservative observation strategy.

As a second factor influencing long-term outcome, a thoracolumbar localization was shown to be associated with a less favorable neurological status on follow-up. The implications of these findings in our cohort are difficult to evaluate reliably since only 2 patients had lesions in the thoracolumbar spine; thus, statistical significance in the univariate analysis must be interpreted carefully. Both patients with thoracolumbar ISC presented with an ASIA Grade $\mathrm{C}$ on long-term follow-up, which reflected the preoperative status (ASIA Grade C).

In $58.3 \%$ of cases, $\mathrm{a} \mathrm{CO}_{2}$ laser was used. Given the institutional experience of our center, especially for myelotomy and intramedullary preparation, the use of a laser enabled the surgeon to dissect without any traction to the surrounding nervous tissue. In clinical practice, once a surgeon becomes familiar with the device, the $\mathrm{CO}_{2}$ laser proves to be an effective and safe operative tool that ensures as gentle preparation as possible. ${ }^{9,26}$ A microsurgical alternative to the $\mathrm{CO}_{2}$ laser is the cavitational ultrasonic surgical aspirator (CUSA) in spinal cord tumor surgery., ${ }^{4,7}$

Regarding the bony approach to the spinal cord, vari-

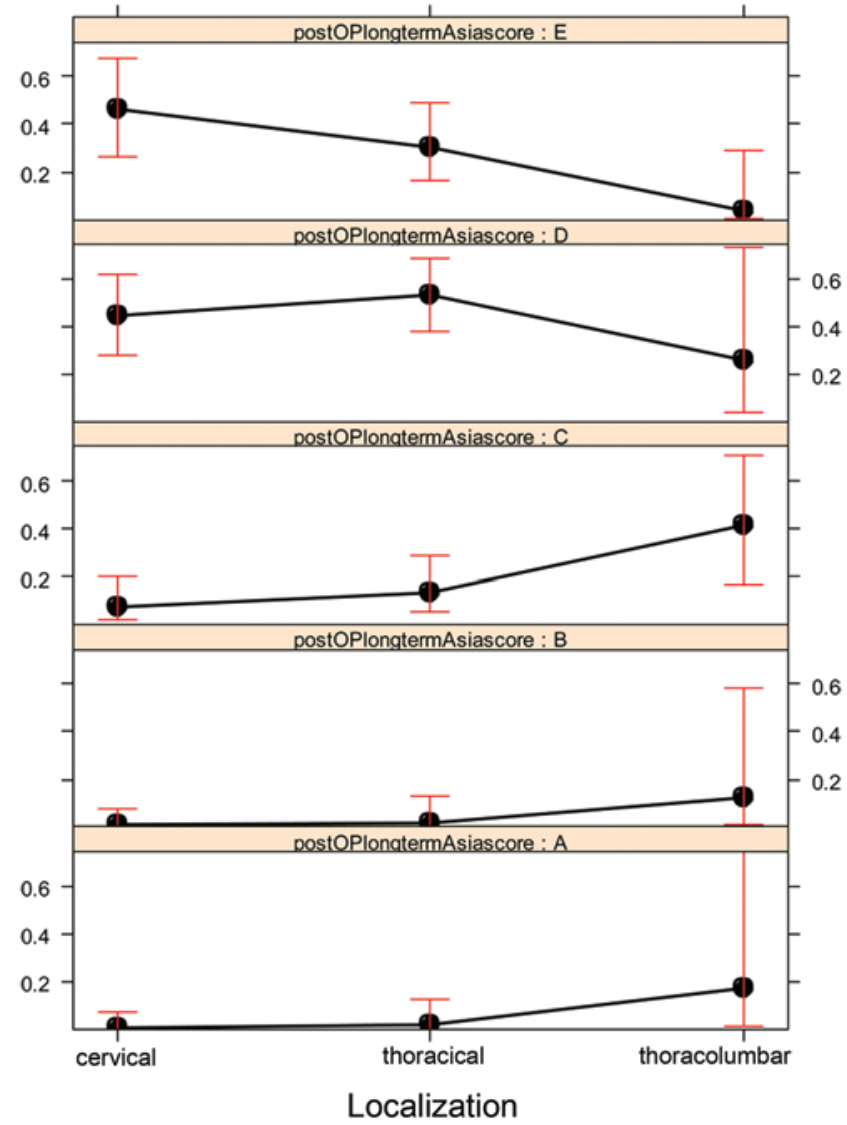

FIG. 7. Localization effect plot: probability of postoperative long-term ASIA Grades A-E correlated with ISC localization. Red bars display confidence intervals for each location in the tested ASIA grade. Cervical and thoracic locations are most likely associated with ASIA Grade D or $\mathrm{E}$, whereas a thoracolumbar ISC is associated with a higher probability of an ASIA Grade C on long-term follow-up.

ous strategies ranging from keyhole approaches (for example, hemilaminectomies) to more extensive multiple-level laminectomies in large ISC were applied in our cohort. Recent approaches focus on nondestructive, minimally invasive strategies if possible to obtain an adequate anatomical overview. If multilevel laminectomies in the cervical spine are necessary (due to the need for gently rotating the spinal cord to reach the lateral lesion or the extent of the cavernoma), they are routinely combined with dorsal stabilization techniques to avoid kyphotic malalignment. ${ }^{19}$ To access ventrally located cervical cavernomas reaching the pial surface, a custom-tailored approach via partial corpectomy has been shown to be feasible. In these rare cases, the broad dorsal exposures of the spinal cord can be avoided by rotating the spinal cord to reach the pathology. On the one hand, however, this approach requires extensive experience evaluating IOM data, in particular D-wave monitoring data (in this case, the stimulating electrode was placed ventrally); on the other hand, it requires an excellent understanding of the vascular supply of the spinal cord. The routine use of IOM was established in 1997, whereas the use of the $\mathrm{CO}_{2}$ laser was established much earlier in our department, that is, from the beginning of the presented series (mid-1980s). Intraoperative electrophysi- 
ological monitoring has proven to be an especially helpful surgical tool capable of influencing the intraoperative strategy. However, sometimes electrophysiological deteriorations seem to be related to a surgical maneuver but are eventually proven to be false negative. In these cases, the intraoperative situation together with the electrophysiological findings and the experience of the operating surgeon influence the decision of whether to modify the surgical strategy or to continue with the operation as planned.

Additionally, D-wave alterations were recently shown to be a consistent parameter predicting the postoperative neurological status with higher reliability than MEPs. ${ }^{12,33}$ As clinical improvements often take years to develop, some of the recently treated patients (5 within the last 2 years) might undergo additional improvement in the future, possibly improving the general long-term outcome of the cohort presented.

A limitation of this study was its design as a retrospective analysis.

\section{Conclusions}

Microsurgical treatment of ISC displays an unrivaled safe and efficient causative treatment option and should be considered when patients present with symptoms. On long-term follow-up, more than $93 \%$ of patients present with an unchanged or improved neurological status after complete removal of the pathology, as compared with their preoperative status. Risk factors for an unfavorable outcome (ASIA Grades A-C) were a low preoperative ASIA and EC grade and a pathology located in the thoracolumbar region. Given the rarity of the ISC and the necessity for custom-tailored surgical approaches, treatment should be reserved for spinal neurovascular centers offering the complete spectrum of microsurgical therapies including IOM.

\section{Acknowledgments}

We thank Dr. D. Winkler for his kind support in data collection and Nicklas von Spreckelsen for his support creating graphs.

\section{References}

1. Anson JA, Spetzler RF: Surgical resection of intramedullary spinal cord cavernous malformations. J Neurosurg 78:446451,1993

2. Badhiwala JH, Farrokhyar F, Alhazzani W, Yarascavitch B, Aref M, Algird A, et al: Surgical outcomes and natural history of intramedullary spinal cord cavernous malformations: a single-center series and meta-analysis of individual patient data: Clinic article. J Neurosurg Spine 21:662-676, 2014

3. Bozinov O, Burkhardt JK, Woernle CM, Hagel V, Ulrich NH, Krayenbühl N, et al: Intra-operative high frequency ultrasound improves surgery of intramedullary cavernous malformations. Neurosurg Rev 35:269-275, 2012

4. Brotchi J, Noterman J, Baleriaux D: Surgery of intramedullary spinal cord tumours. Acta Neurochir (Wien) 116:176178,1992

5. Bruneau M, Bijlenga P, Reverdin A, Rilliet B, Regli L, Villemure JG, et al: Early surgery for brainstem cavernomas. Acta Neurochir (Wien) 148:405-414, 2006

6. Canavero S, Pagni CA, Duca S, Bradac GB: Spinal intramedullary cavernous angiomas: a literature meta-analysis. Surg Neurol 41:381-388, 1994
7. Cheng JS, Ivan ME, Stapleton CJ, Quinones-Hinojosa A, Gupta N, Auguste KI: Intraoperative changes in transcranial motor evoked potentials and somatosensory evoked potentials predicting outcome in children with intramedullary spinal cord tumors. J Neurosurg Pediatr 13:591-599, 2014

8. Choi GH, Kim KN, Lee S, Ji GY, Oh JK, Kim TY, et al: The clinical features and surgical outcomes of patients with intramedullary spinal cord cavernous malformations. Acta Neurochir (Wien) 153:1677-1685, 2011

9. Consiglieri GD, Killory BD, Germain RS, Spetzler RF: Utility of the $\mathrm{CO} 2$ laser in the microsurgical resection of cavernous malformations. World Neurosurg 79:714-718, 2013

10. Cooper PR, Epstein F: Radical resection of intramedullary spinal cord tumors in adults. Recent experience in 29 patients. J Neurosurg 63:492-499, 1985

11. Cristante L, Hermann HD: Radical excision of intramedullary cavernous angiomas. Neurosurgery 43:424-431, 1998

12. Deletis V, Sala F: Intraoperative neurophysiological monitoring of the spinal cord during spinal cord and spine surgery: a review focus on the corticospinal tracts. Clin Neurophysiol 119:248-264, 2008

13. Deutsch H, Jallo GI, Faktorovich A, Epstein F: Spinal intramedullary cavernoma: clinical presentation and surgical outcome. J Neurosurg 93 (1 Suppl):65-70, 2000

14. Eicker S, Turowski B, Steiger HJ, Hänggi D: [Diagnostic work-up and therapy of spinal vascular malformations: an update.] Nervenarzt 81:719-726, 2010 (Ger)

15. Eicker SO, Szelényi A, Mathys C, Steiger HJ, Hänggi D: Custom-tailored minimally invasive partial C2-corpectomy for ventrally located intramedullary cavernous malformation. Neurosurg Rev 36:487-491, 2013 (Erratum in Neurosurg Rev 36:493, 2013)

16. El-Koussy M, Stepper F, Spreng A, Lukes A, Gralla J, Brekenfeld C, et al: Incidence, clinical presentation and imaging findings of cavernous malformations of the CNS. A twentyyear experience. Swiss Med Wkly 141:w13172, 2011

17. Gross BA, Du R, Popp AJ, Day AL: Intramedullary spinal cord cavernous malformations. Neurosurg Focus 29(3):E14, 2010

18. Jallo GI, Freed D, Zareck M, Epstein F, Kothbauer KF: Clinical presentation and optimal management for intramedullary cavernous malformations. Neurosurg Focus 21(1):e10, 2006

19. Joaquim AF, Cheng I, Patel AA: Postoperative spinal deformity after treatment of intracanal spine lesions. Spine $\mathbf{J}$ 12:1067-1074, 2012

20. Kim KM, Chung CK, Huh W, Lee WJ, Park SB, Kim CH, et al: Clinical outcomes of conservative management of spinal cord cavernous angiomas. Acta Neurochir (Wien) 155:1209-1214, 2013

21. Kirshblum SC, Waring W, Biering-Sorensen F, Burns SP, Johansen M, Schmidt-Read M, et al: Reference for the 2011 revision of the International Standards for Neurological Classification of Spinal Cord Injury. J Spinal Cord Med 34:547554,2011

22. Kivelev J, Niemelä M, Hernesniemi J: Outcome after microsurgery in 14 patients with spinal cavernomas and review of the literature. J Neurosurg Spine 13:524-534, 2010

23. Kivelev J, Niemelä M, Hernesniemi J: Treatment strategies in cavernomas of the brain and spine. J Clin Neurosci 19:491497, 2012

24. Kothbauer KF, Deletis V, Epstein FJ: Motor-evoked potential monitoring for intramedullary spinal cord tumor surgery: correlation of clinical and neurophysiological data in a series of 100 consecutive procedures. Neurosurg Focus 4(5):e1, 1998

25. Liang JT, Bao YH, Zhang HQ, Huo LR, Wang ZY, Ling F: Management and prognosis of symptomatic patients with intramedullary spinal cord cavernoma: clinical article. J Neurosurg Spine 15:447-456, 2011 
26. Lin LM, Sciubba DM, Jallo GI: Neurosurgical applications of laser technology. Surg Technol Int 18:63-69, 2009

27. Maslehaty H, Barth H, Petridis AK, Doukas A, Mehdorn HM: Symptomatic spinal cavernous malformations: indication for microsurgical treatment and outcome. Eur Spine $\mathbf{J}$ 20:1765-1770, 2011

28. McCormick PC, Michelsen WJ, Post KD, Carmel PW, Stein BM: Cavernous malformations of the spinal cord. Neurosurgery 23:459-463, 1988

29. Mitha AP, Turner JD, Abla AA, Vishteh AG, Spetzler RF: Outcomes following resection of intramedullary spinal cord cavernous malformations: a 25 -year experience. J Neurosurg Spine 14:605-611, 2011

30. Mitha AP, Turner JD, Spetzler RF: Surgical approaches to intramedullary cavernous malformations of the spinal cord. Neurosurgery 68 (2 Suppl Operative):317-324, 2011

31. Ogilvy CS, Louis DN, Ojemann RG: Intramedullary cavernous angiomas of the spinal cord: clinical presentation, pathological features, and surgical management. Neurosurgery 31:219-230, 1992

32. Regelsberger J, Fritzsche E, Langer N, Westphal M: Intraoperative sonography of intra- and extramedullary tumors. Ultrasound Med Biol 31:593-598, 2005

33. Sala F, Palandri G, Basso E, Lanteri P, Deletis V, Faccioli F, et al: Motor evoked potential monitoring improves outcome after surgery for intramedullary spinal cord tumors: a historical control study. Neurosurgery 58:1129-1143, 2006

34. Sandalcioglu IE, Wiedemayer H, Gasser T, Asgari S, Engelhorn T, Stolke D: Intramedullary spinal cord cavernous malformations: clinical features and risk of hemorrhage. Neurosurg Rev 26:253-256, 2003

35. Spetzger U, Gilsbach JM, Bertalanffy H: Cavernous angiomas of the spinal cord clinical presentation, surgical strategy, and postoperative results. Acta Neurochir (Wien) 134:200206, 1995

36. Steiger HJ, Turowski B, Hänggi D: Prognostic factors for the outcome of surgical and conservative treatment of symptom- atic spinal cord cavernous malformations: a review of a series of 20 patients. Neurosurg Focus 29(3):E13, 2010

37. Wachter D, Psychogios M, Gilsbach JM, Rohde V: Spinal cord cavernoma-operative strategy and results in 30 patients. J Neurol Surg A Cent Eur Neurosurg 73:125-131, 2012

38. Zevgaridis D, Medele RJ, Hamburger C, Steiger HJ, Reulen $\mathrm{HJ}$ : Cavernous haemangiomas of the spinal cord. A review of 117 cases. Acta Neurochir (Wien) 141:237-245, 1999

\section{Author Contributions}

Conception and design: Reitz, Raimund, Fritzsche, Westphal, Eicker. Acquisition of data: Reitz, Burkhardt, Raimund, Fritzsche. Analysis and interpretation of data: Reitz, Vettorazzi, Raimund, Fritzsche, Regelsberger, Eicker. Drafting the article: Reitz, Raimund, Regelsberger, Westphal, Eicker. Critically revising the article: Reitz, Burkhardt, Vettorazzi, Schmidt, Westphal. Reviewed submitted version of manuscript: Reitz. Approved the final version of the manuscript on behalf of all authors: Reitz. Statistical analysis: Reitz. Administrative/technical/material support: Reitz. Study supervision: Reitz, Eicker.

\section{Supplemental Information}

Previous Presentation

Portions of this work were presented as proceedings at the 9th Annual Meeting of the German Spine Society held in Leipzig, Germany, on December 12, 2014.

\section{Correspondence}

Matthias Reitz, Department of Neurological Surgery, Section Neurosurgical Spinal Surgery, University Medical Center Hamburg-Eppendorf, Martinistr. 52, Hamburg 20246, Germany. email:mareitz@uke.de. 